\title{
Adipocytokines, Body Composition, and Fitness in Children
}

\author{
DAN NEMET, PING WANG, TOHRU FUNAHASHI, YUJI MATSUZAWA, SACHIYO TANAKA, \\ LASZLO ENGELMAN, AND DAN M. COOPER \\ Department of Pediatrics, Center for the Study of Health Effects of Exercise in Children, University of \\ California, Irvine, California, U.S.A. [D.N., P.W., L.E., D.M.C.]; Department of Internal Medicine and \\ Molecular Science, Osaka University, Osaka, Japan [T.F., Y.M., S.T.]
}

\begin{abstract}
Recent evidence suggests a role for adipose derived cytokines (adipocytokines) such as tumor necrosis factor- $\alpha$ (TNF- $\alpha$ ), IL-6, and the recently discovered adiponectin in the mechanism of impaired glucose regulation and atherosclerosis in adults. However, the relationship between adipocytokines and body composition, fasting insulin, and fitness is virtually unknown children. Fasting blood sampling was performed in 30 healthy, predominately Hispanic- and Asian-American children (16 boys, mean age $12.7 \pm 0.1 \mathrm{y}$ old) from a lower socioeconomic area in Los Angeles. Adiposity was measured by dual x-ray absorptiometry (DEXA); and peak oxygen uptake using cycle ergometry. Adiponectin (mean $10.8 \pm 0.8 \mu \mathrm{g} / \mathrm{mL}$ ) was inversely correlated with body mass index (BMI, as percentile by age) $(r=-0.48, p=$ $0.011)$ and fat mass $(r=-0.43, p=0.03)$. In contrast, TNF- $\alpha$ and IL-6 were both positively correlated with BMI and fat mass. Adiponectin was inversely correlated with fasting insulin $(r=$ $-0.52, p=0.006$ ), but no correlations were found for insulin and either TNF- $\alpha$ or IL-6. Adiponectin was correlated with HDL
\end{abstract}

\section{ABSTRACT}

( $r=0.448, p=0.019)$. Paradoxically, peak oxygen consumption (an indicator of fitness) was negatively correlated with adiponectin levels $(r=-0.471, p=0.013)$ and positively correlated with TNF- $\alpha(r=0.560, p=0.002)$. In children, adipocytokines are correlated with fat mass, insulin sensitivity, and cardiovascular risk factors in a manner that is qualitatively similar to relationships recently observed in adults. In more obese children, the mass of fat tissue may attenuate potentially positive effects of fitness on circulating levels of adiponectin and TNF- $\alpha$. The novel data on adiponectin suggest that deleterious dysregulation of adipocytokines associated with obesity may occur relatively early in life. (Pediatr Res 53: 148-152, 2003)
TNF- $\boldsymbol{\alpha}$, tumor necrosis factor- $\alpha$
DEXA, dual x-ray absorptiometry
BMI, body mass index
$\dot{\mathrm{V}}_{\mathbf{2}}$, oxygen consumption

Abbreviation
Obesity in children is clinically worrisome because it is associated with low levels of physical fitness and poor diet leading to increased risk of metabolic or cardiovascular diseases later in life (1). Obesity can also reflect the presence of disease such as type 2 diabetes mellitus, now increasingly found in children and adolescents (2). The mechanisms that link adipose tissue with pathologic processes of insulin resistance and hyperlipidemia are poorly understood. As a consequence, clinicians currently lack diagnostic criteria for determining the level of adiposity above which significant metabolic dysregulations occur and aggressive treatment should be implemented.

Received April 26, 2002; accepted July 4, 2002.

Correspondence: Dan M. Cooper, M.D., Professor of Pediatrics-UCI College of Medicine, Clinical Research Center, Bldg 25, ZOT 4094-03, 101 The City Drive, Orange, CA 92868, U.S.A.; e-mail: dcooper@uci.edu

Supported by grants MO1-RR00827 and HD 23969 from the National Institutes of Health. D.N. is a Postdoctoral Research Fellow of the Joseph W. Drown Foundation.

DOI: 10.1203/01.PDR.0000039766.53698.3D
The fat tissue, once considered a metabolically inert tissue serving only as a depot for energy substrate and insulation, is now known to be metabolically active. Recent investigations have focused on a family of adipose derived cellular mediators (adipocytokines), including TNF- $\alpha$ and IL-6. The importance of these agents is that they are produced by fat cells and are known to regulate a host of physiologic processes directly tied to carbohydrate and fat metabolism and the development of obesity complications such as diabetes and atherosclerosis (3).

The recently discovered adipocytokine adiponectin is the most abundant gene product in fat tissue (4). In contrast to all other known adipocytokines, adiponectin levels are known to be decreased in obese adults, and in individuals with either type 2 diabetes or coronary artery disease (5). There is mounting evidence that adiponectin is involved in the pathogenesis of type 2 diabetes and atherosclerosis by its effects on TNF- $\alpha$ and the expression of certain endothelial adhesion molecules (6). Consequently, the regulation and function of adiponectin has been the subject of substantial recent investigation. To our 
knowledge, the relationship of adiponectin to body fat, fitness, and other adipocytokines has yet to be studied in children.

The purpose of this study was to examine these anatomic and physiologic variables in a population of pre- and early adolescent children from an inner-city, lower socioeconomic status - conditions that are associated with increased incidence of obesity in preadolescents (7). Specifically, we hypothesized that adiposity, poor fitness, and insulin resistance would be positively correlated with the adipocytokines IL- 6 and TNF- $\alpha$; but negatively correlated with the newly discovered adiponectin.

\section{METHODS}

Sample population. The study was approved by the Institutional Review Board, University of California, Irvine (UCI) and informed consent as well as assent were obtained. Thirty healthy, predominately lower socioeconomic children volunteered to participate in the study (Table 1). The volunteers were all students attending a single middle school in the Los Angeles area. We recognized that a strictly random sampling of all eligible students is virtually impossible given that the process of informed consent is based on the willingness of individual children and their parents to participate.

Height, weight, and BMI measurements. Standard, calibrated scales and stadiometers were used to determine height, weight, and BMI. Because BMI changes with age, we calculated BMI percentile for each child using the recently published standards from the Centers for Disease Control, National Center for Health Statistics (8).

Assessment of body fat by DEXA. Fat mass was measured by DEXA using a hologic QDR 4500 densitometer (Hologic, Inc. Bedford, MA, U.S.A.), a well-established technique for assessing body composition in children. Subjects were scanned in light clothing, while lying flat on their backs. DEXA scans were performed and analyzed using pediatric software. On the days of each test, the DEXA machine was calibrated using the procedures provided by the manufacturer.

Measurement of cardiorespiratory fitness. Each subject performed a ramp-type progressive exercise test on a cycle ergometer in which the subject exercised to the limit of his tolerance. Subjects were vigorously encouraged during the high-intensity phases of the exercise protocol. Gas exchange was measured breath-by-breath (9) and the $\dot{\mathrm{V}}_{2}$ peak was

Table 1. Age, gender, ethnic, anthropometric, and peak $\mathrm{VO}_{2}$ values $(\mathrm{n}=30)$

\begin{tabular}{lc} 
Age $($ years $)$ & $12.7 \pm 0.1($ range $12-14)$ \\
Gender $($ Male/Female) & $16 / 14$ \\
Origin $($ Hispanic/Asian) & $14 / 16$ \\
Height $(\mathrm{cm})$ & $158.2 \pm 1.3($ range $143-171)$ \\
Weight $(\mathrm{kg})$ & $57.3 \pm 3.1($ range $38.9-102)$ \\
$\mathrm{BMI}\left(\mathrm{kg} / \mathrm{m}^{2}\right)$ & $22.8 \pm 1.1($ range $16.6-34.9)$ \\
$\mathrm{BMI} \mathrm{percentile} \mathrm{(for} \mathrm{age)}$ & $68.3 \pm 5.1($ range $16.9-99.4)$ \\
Peak $\mathrm{VO}_{2}(\mathrm{~L} / \mathrm{min})$ & $1.64 \pm 0.07($ range $1.07-2.59)$ \\
Peak $\mathrm{VO}_{2}(\mathrm{ml} / \mathrm{min} / \mathrm{kg})$ & $29.5 \pm 1.4($ range $14.6-53.8)$ \\
Fat mass $(\mathrm{kg})$ & $16.2 \pm 1.9($ range $4.7-38.9)$ \\
Fat percent & $26.8 \pm 1.9($ range $9.7-44.5)$ \\
\hline
\end{tabular}

Data presented as mean $\pm \mathrm{SEM}$. determined as previously described for children and adolescents (10).

Serum measurements. Fasting, early morning blood measurements were obtained by standard phlebotomy.

$\boldsymbol{T N F}-\boldsymbol{\alpha}$. TNF- $\alpha$ levels were determined by ELISA with the use of the Quantikine high-sensitivity kit (R \& D Systems; Minneapolis, MN, U.S.A.). Intra-assay coefficient of variation (CV) was $8.7-14.8 \%$, interassay CV was $16.1-22.6 \%$, and the sensitivity was $0.18 \mathrm{pg} / \mathrm{mL}$.

IL-6. IL-6 serum levels were determined by ELISA with the use of the Quantikine high-sensitivity kit (R \& D Systems). Intra-assay CV was $3.8-11.1 \%$, interassay CV was $7.1-29.5 \%$, and the sensitivity was $0.094 \mathrm{pg} / \mathrm{mL}$.

$\boldsymbol{H D L}$. Serum HDL levels were performed using standard techniques (Synchron CX-7, Beckman Coulter, Inc., Fullerton, CA, U.S.A.). HDL intra- and interassay CV were $4.4 \%$ and $5.4 \%$, respectively. HDL sensitivity was $5 \mathrm{mg} / \mathrm{dL}$.

Adiponectin. Adiponectin serum levels were determined by ELISA system developed for human adiponectin measurement as described previously (5). Intra-assay $\mathrm{CV}$ was $3.3 \%$, interassay CV was $7.4 \%$. These assays were performed in the Department of Internal Medicine and Molecular Science, Osaka University, Osaka, Japan.

Insulin. Insulin serum levels were determined by ELISA with the use of the DSL-10-1600 Active kit (Diagnostic System Laboratories, Webster, TX, U.S.A.). Intra-assay CV was $1.3-2.6 \%$, interassay $\mathrm{CV}$ was $5.2-6.2 \%$, and the sensitivity was $0.26 \mu \mathrm{IU} / \mathrm{mL}$.

Statistical analysis. Correlation and standard linear regression analyses were used to determine the correlation coefficients between growth factors, cytokines, BMI, and indexes of body composition and fitness. Data are presented as mean \pm SEM.

\section{RESULTS}

Body composition, circulating adipocytokines, and peak $\dot{\boldsymbol{V}}_{\mathbf{O}_{2}}$. Subject characteristics are presented in Table 1 . There were no differences in the mean values of these measurements between boys and girls (data not shown). Mean and the range of circulating levels of adipocytokines, fasting insulin, and HDL are presented in Table 2 . We did note a significantly lower level of adiponectin in boys $(9.02 \pm 0.90 \mu \mathrm{g} / \mathrm{mL})$ compared with girls $(12.62 \pm 1.31 \mu \mathrm{g} / \mathrm{mL}, p=0.035)$.

BMI percentile (all subjects) was positively correlated with IL-6 $(r=0.398, p=0.04)$ and TNF- $\alpha(r=0.384, p=0.048)$, and negatively correlated with adiponectin $(r=-0.481, p=$ 0.011) (Fig. 1). Similarly, fat mass (in kilograms) measured by

Table 2. Circulating adiponecytokines, fasting insulin, and $H D L$

\begin{tabular}{lc}
\hline Adiponectin $(\mu \mathrm{g} / \mathrm{ml})$ & $10.8 \pm 0.8$ (range 4.2-20.8) \\
$\mathrm{IL}-6(\mathrm{pg} / \mathrm{ml})$ & $2.6 \pm 0.2($ range $0.5-5.1)$ \\
$\mathrm{TNF}-\alpha(\mathrm{pg} / \mathrm{ml})$ & $3.3 \pm 0.2(1.5-5.0)$ \\
Insulin $(\mu \mathrm{IU} / \mathrm{ml})$ (Normal Value: $7-24$ & $9.62 \pm 1.3$ (range 1.9-30.5) \\
$\quad \mu \mathrm{IU} / \mathrm{ml})$ & \\
$\mathrm{HDL}(\mathrm{mg} / \mathrm{dl})($ Normal Value: $35-84 \mathrm{mg} / \mathrm{ml})$ & $58.2 \pm 2.3$ (range 31-80) \\
\hline
\end{tabular}

Data presented as mean \pm SEM.

Normal values adapted from: Nelson Textbook of Pediatrics $16^{\text {th }}$ edition, W.B. Saunders 2000. 


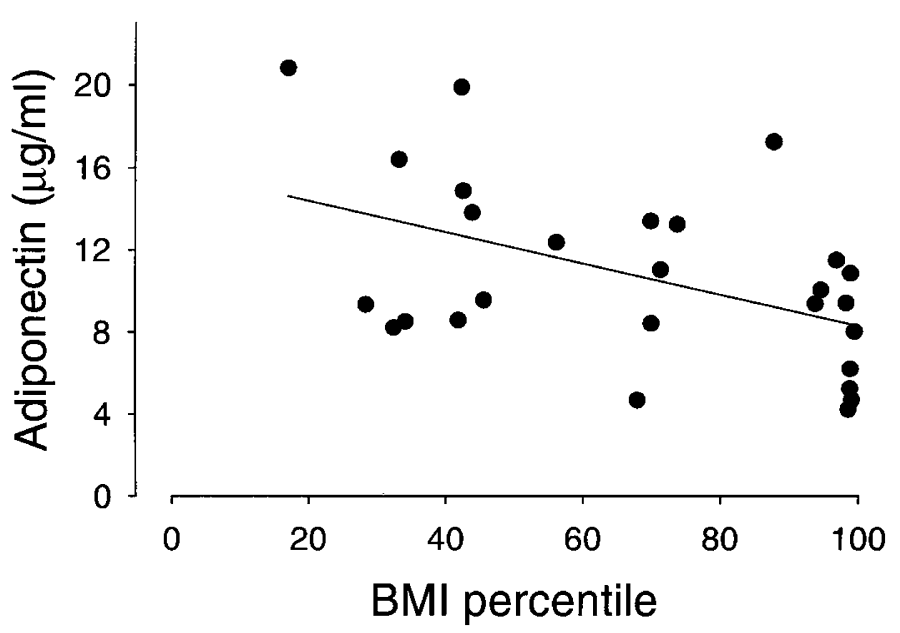

Figure 1. Relationship between adiponectin and BMI percentile. There was a significant inverse correlation between these two variables.

DEXA was positively correlated with IL-6 $(r=0.487, p=$ $0.01)$ and TNF- $\alpha(r=0.448, p=0.019)$, and negatively correlated with adiponectin $(r=-0.427, p=0.026)$ (Fig. 2). Percent fat was positively correlated with IL-6 $(r=0.46, p=$ $0.016)$ and negatively correlated with adiponectin $(r=-0.39$, $p=0.04)$. Peak $\dot{\mathrm{V}}_{2}$ was negatively correlated with adiponectin levels $(r=-0.471, p=0.013)$ and positively correlated with TNF- $\alpha(r=0.560, p=0.002)$.

Circulating adipocytokines and insulin. Fasting insulin levels were negatively correlated with adiponectin $(r=-0.524$, $p=0.006$ ) (Fig. 3). No significant correlations were found between fasting insulin and either TNF- $\alpha$ or IL-6. Adiponectin was inversely correlated with TNF- $\alpha(r=-0.562, p=0.002)$ (Fig. 3). No correlation was found between adiponectin and IL-6.

Adipocytokines and HDL. HDL levels were positively correlated with adiponectin $(r=0.448, p=0.019)$. There were no significant correlations between HDL and either TNF- $\alpha$ or IL-6.

\section{DISCUSSION}

This study demonstrates for the first time in children, the relationship between the adipocytokines (adiponectin, TNF- $\alpha$, and IL-6) with body composition, fitness, markers of insulin resistance, and cardiovascular risk. As noted above, volunteers for this study were recruited from a population at high risk for the development of obesity relatively early in life, and, in fact, the mean BMI percentile was greater than average at $68.3 \pm$ 5.1. The children in our study with higher body fat stores had higher levels of TNF- $\alpha$ and IL-6, and lower levels of adiponectin (Figs. 1 and 2). Finally, although no correlations were observed between fasting insulin and either TNF- $\alpha$ or IL-6, adiponectin was negatively correlated with fasting insulin (Fig. $3)$.

Although this study did not include adults, the adiponectin assay from previous studies in adults were performed in the same laboratory using a uniform technique. When compared with these previous studies, this initial report suggests that adiponectin levels may be higher in children compared with
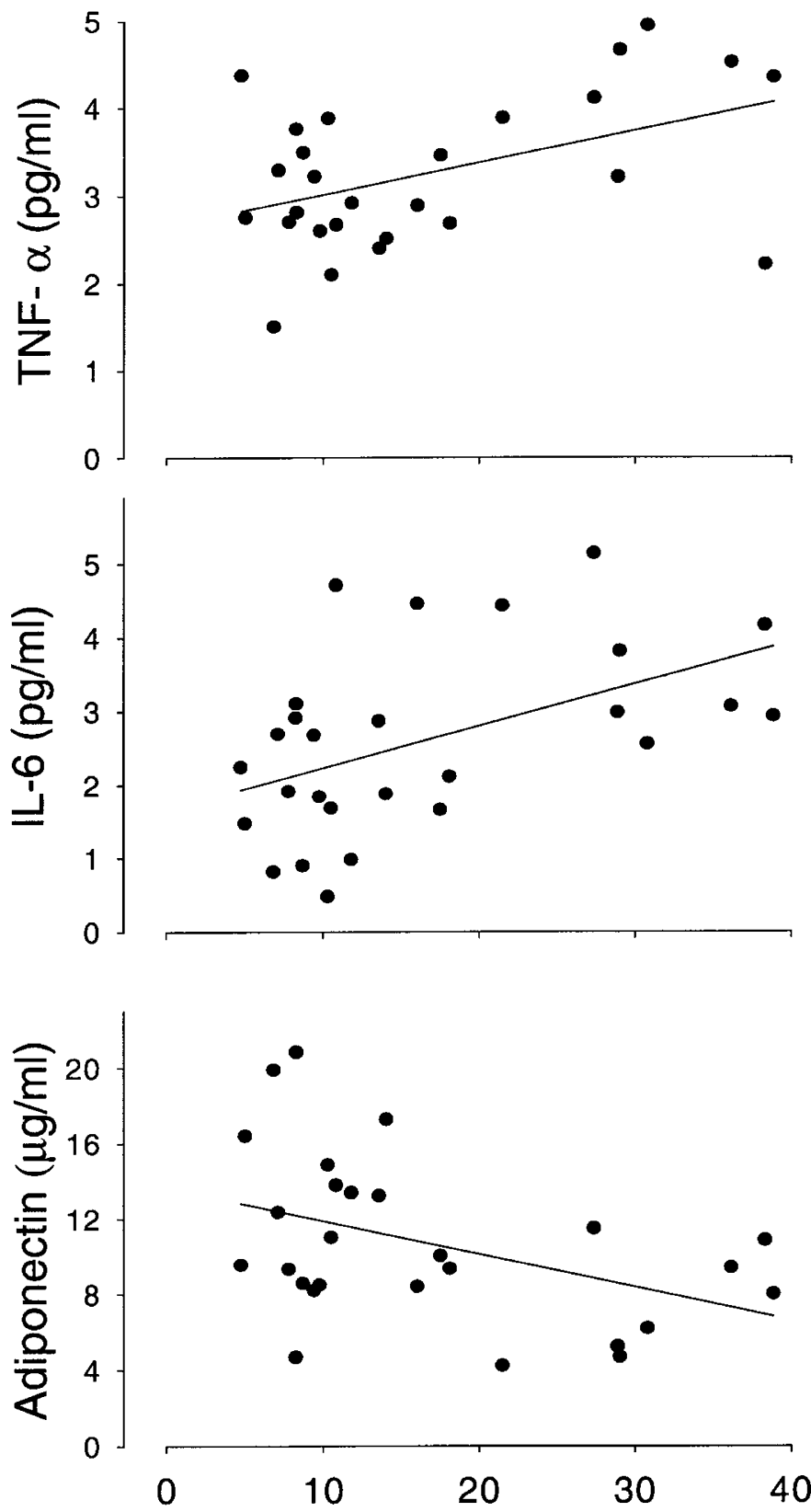

\section{Fat Mass $(\mathrm{kg})$}

Figure 2. Relationship between fat mass (measured by DEXA) and circulating adipocytokines. Both TNF- $\alpha$ and IL-6 were significantly correlated with fat mass (top two panels). In contrast, adiponectin was inversely correlated with fat mass (bottom panel).

adults. For example, Arita and co-workers (5) reported mean adiponectin levels of about $8.9 \mu \mathrm{g} / \mathrm{mL}$ (ranging from 1.9 to $17.0 \mu \mathrm{g} / \mathrm{mL}$ ) in nonobese adults, whereas the mean level for children whose BMI was less than the 85th percentile in our study was $12.1 \mu \mathrm{g} / \mathrm{mL}$ (ranging from 4.6 to $20.8 \mu \mathrm{g} / \mathrm{mL}$ ). These generally higher levels may reflect the fact that children have lower BMI and relatively lower fat than adults (8).

We also noted that the boys in our study had lower levels of adiponectin than did the girls, despite the fact that there were no significant differences in fat mass. This gender difference was also noted previously in adults (5). Factors like gender and 
ethnicity may also play a role in adiponectin regulation among different populations (11), and additional, larger sample size studies will clearly be needed in children to fully elucidate the impact of gender and ethnicity on circulating adipocytokines.

As fat mass increases in obesity, adipocytokines become involved in a number of metabolic and hormonal adjustments leading to impaired glucoregulation and atherosclerosis. IL-6 induces an acute phase response, increases basal glucose uptake, alters insulin sensitivity, and adversely affects triglyceride metabolism (12). Fat-derived TNF- $\alpha$ acts on other tissues to impair the function of the insulin receptor and hasten the development of insulin resistance $(13,14)$. Obesity alterations in adiponectin concentrations may also contribute to insulin resistance through a variety of mechanisms: first, adiponectin actually inhibits TNF- $\alpha$ secretion (6) (see Fig. 3), and as adiponectin levels decrease, this attenuation likely diminishes as well. Moreover, Yamauchi and co-workers (15) recently reported in an animal model that exogenously administered adiponectin reverses insulin resistance associated with both lipoatrophy and obesity by altering triglyceride metabolism in the muscle and liver.
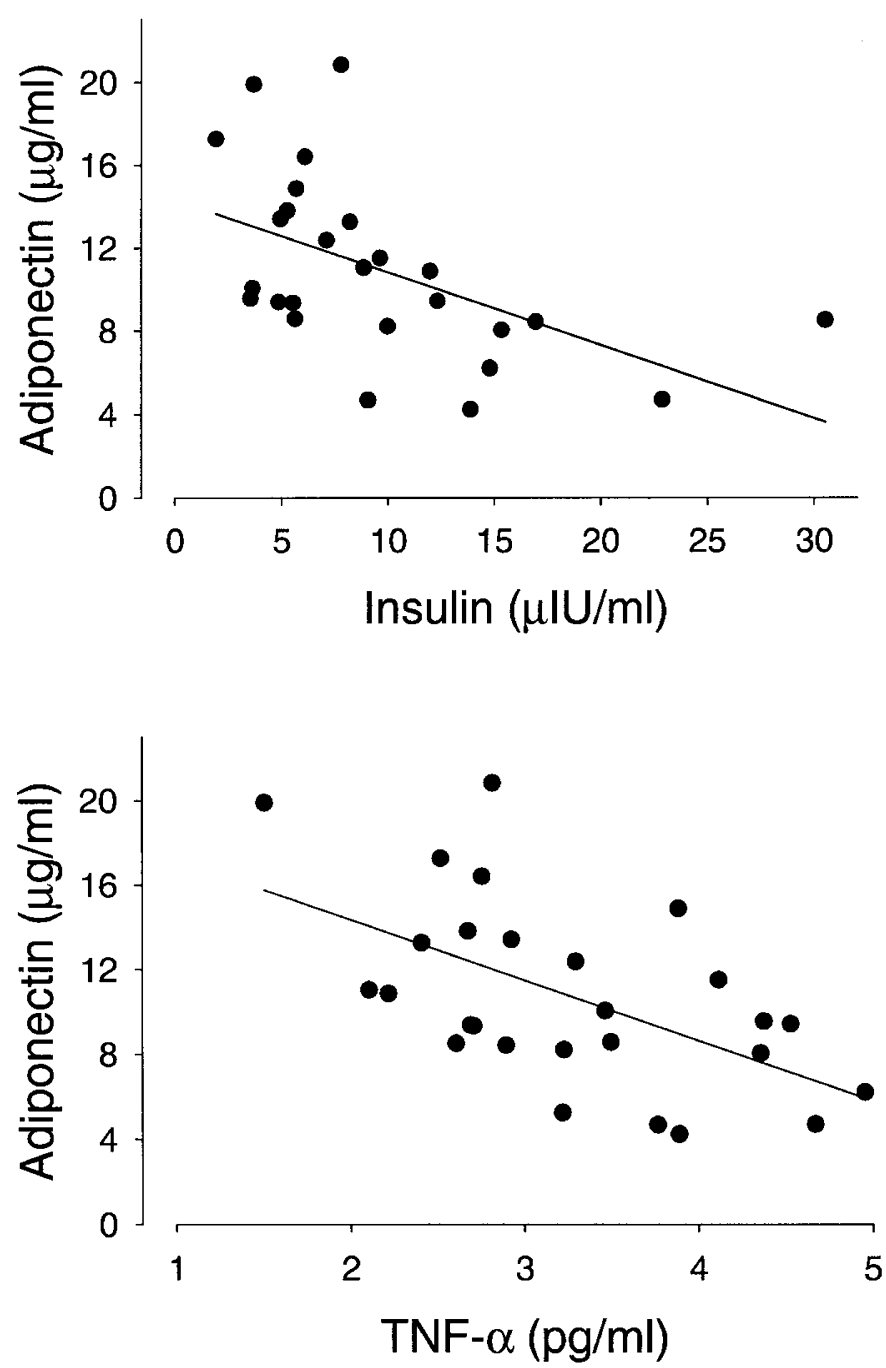

Figure 3. Relationship between adiponectin and fasting insulin (top panel) and TNF- $\alpha$ (bottom panel). Adiponectin was inversely correlated with both fasting insulin and TNF- $\alpha$.
Adiponectin was found to be positively correlated with HDL levels in the children studied, and higher HDL indicates a reduced risk of atherosclerotic cardiovascular disease (16). As is the case with insulin resistance, the role of adiponectin in reducing cardiovascular risk may derive primarily from the fact that adiponectin inhibits biologic activity of TNF- $\alpha$. In vitro studies demonstrated that high levels of adiponectin interfere with the process of atherosclerosis by inhibiting the TNF- $\alpha$ induced expression of adhesion molecules in endothelial cells and the secretion of TNF- $\alpha$ from monocyte-macrophages (17, 18 ), as well as by suppressing lipid accumulation in monocytemacrophage cells, a key step in the pathogenesis of atherosclerosis (19). The converse is also true, namely, high levels of TNF- $\alpha$ antagonize adiponectin $(6,20)$. Along these lines, we found a significant inverse correlation between adiponectin and TNF- $\alpha$ (Fig. 3).

We found that adiponectin was negatively correlated with peak $\dot{\mathrm{V}}_{2}$, a counterintuitive observation inasmuch as it would have been reasonable to expect fitter subjects to have less fat mass and, consequently, higher levels of adiponectin. However, although the obesity syndrome is characterized primarily by excess fat, obese adults and children have a relatively large muscle mass as well. Muscle mass, in turn, is the major determinant of most physiologic indicators of fitness like peak $\dot{\mathrm{V}}_{2}$. Thus, the seemingly paradoxical association between decreased adiponectin and peak $\dot{\mathrm{V}}_{2}$ levels is explained by the fact that the more obese children in our study tended to have simultaneously 1) lower adiponectin due to greater fat mass; and 2) increased peak $\dot{\mathrm{V}}_{2}$ due to greater muscle mass. Clearly, higher levels of physical activity in children are associated with an augmentation of muscle mass and decrease in fat (21), which in and of itself would likely lead to increased adiponectin and reduced IL- 6 and TNF- $\alpha$. Exercise improves insulin resistance in large part by altering glucose transporters in the muscle (22-24), but our data suggest that potentially beneficial effects of exercise in obese children may be diminished in the absence of accompanying decreases in fat mass. Whether exercise levels independently influence the concentration of adiponectin or other adipocytokines is simply not known.

Surprisingly, there is not, to our knowledge, a good source for cytokine reference values in healthy children. For example, the reference value for IL- 6 found in the recent edition of Nelson Textbook of Pediatrics (25) is $7 \pm 1 \mathrm{pg} / \mathrm{mL}$, a value that is based on a paper by Krafte-Jacobs and Bock (26) who used 16 "outpatient and hospitalized children without infection or anemia." This reference value is higher than what we (27-29) and others (30) have consistently found in children, and probably reflects the fact that the children studied by Krafte-Jacobs and Bock, who are hospitalized or seen in an outpatient clinic, are likely to have increased circulating proinflammatory cytokines from stress, trauma, and other injuries, even in the absence of overt infection.

In summary, our data support the relatively new concept that in children as well as in adults, obesity influences mediators like the adipocytokines that have been traditionally thought to be involved in the inflammatory process (31). From a clinical perspective, measurement of adipocytokines may become part of the standard evaluation of the obese child and help to 
manage those overweight children who may be at high risk for the development of type 2 diabetes and atherosclerosis later in life.

\section{REFERENCES}

1. Mossberg HO 1989 40-year follow-up of overweight children. Lancet 2:491-493

2. Pinhas-Hamiel O, Zeitler P 1998 Type 2 diabetes in adolescents, no longer rare. Pediatr Rev 19:434-435

3. Trayhurn P, Beattie JH 2001 Physiological role of adipose tissue: white adipose tissue as an endocrine and secretory organ. Proc Nutr Soc 60:329-339

4. Maeda K, Okubo K, Shimomura I, Funahashi T, Matsuzawa Y, Matsubara K 1996 cDNA cloning and expression of a novel adipose specific collagen-like factor, apM1 (AdiPose Most abundant Gene transcript 1). Biochem Biophys Res Commun $221 \cdot 286-289$

5. Arita Y, Kihara S, Ouchi N, Takahashi M, Maeda K, Miyagawa J, Hotta K, Shimomura I, Nakamura T, Miyaoka K, Kuriyama H, Nishida M, Yamashita S, Okubo K, Matsubara K, Muraguchi M, Ohmoto Y, Funahashi T, Matsuzawa Y 1999 Paradoxical decrease of an adipose-specific protein, adiponectin, in obesity. Biochem Biophys Res Commun 257:79-83

6. Maeda N, Takahashi M, Funahashi T, Kihara S, Nishizawa H, Kishida K, Nagaretani H, Matsuda M, Komuro R, Ouchi N, Kuriyama H, Hotta K, Nakamura T, Shimomura I, Matsuzawa Y 2001 PPA Rgamma ligands increase expression and plasma concentrations of adiponectin, an adipose-derived protein. Diabetes 50:2094-2099

7. De Spiegelaere M, Dramaix M, Hennart P 1998 The influence of socioeconomic status on the incidence and evolution of obesity during early adolescence. Int J Obes Relat Metab Disord 22:268-274

8. Kuczmarski RJ, Ogden CL, Grummer-Strawn LM, Flegal KM, Guo SS, Wei R, Mei Z, Curtin LR, Roche AF, Johnson CL 2000 CDC Growth Charts: United States. Centers for Disease Control and Prevention/National Center for Health Statistics Advance Data 314:1-28

9. Beaver WL, Lamarra N, Wasserman K 1981 Breath-by-breath measurement of true alveolar gas exchange. J Appl Physiol 51:1662-1675

10. Cooper DM, Weiler-Ravell D, Whipp BJ, Wasserman K 1984 Aerobic parameters of exercise as a function of body size during growth in children. J Appl Physio 56:628-634

11. Weyer C, Funahashi T, Tanaka S, Hotta K, Matsuzawa Y, Pratley RE, Tataranni PA 2001 Hypoadiponectinemia in obesity and type 2 diabetes: close association with insulin resistance and hyperinsulinemia. J Clin Endocrinol Metab 86:1930-1935

12. Yudkin JS, Kumari M, Humphries SE, Mohamed-Ali V 2000 Inflammation, obesity, stress and coronary heart disease: is interleukin-6 the link? Atherosclerosis 148:209214

13. Shimabukuro M, Zhou YT, Levi M, Unger RH 1998 Fatty acid-induced beta cell apoptosis: a link between obesity and diabetes. Proc Natl Acad Sci U S A 95:24982502

14. Zinman B, Hanley AJ, Harris SB, Kwan J, Fantus IG 1999 Circulating tumor necrosis factor-alpha concentrations in a native Canadian population with high rates of type 2 diabetes mellitus. J Clin Endocrinol Metab 84:272-278

15. Yamauchi T, Kamon J, Waki H, Terauchi Y, Kubota N, Hara K, Mori Y, Ide T, Murakami K, Tsuboyama-Kasaoka N, Ezaki O, Akanuma Y, Gavrilova O, Vinson C, Reitman ML, Kagechika H, Shudo K, Yoda M, Nakano Y, Tobe K, Nagai R, Kimura S, Tomita M, Froguel P, Kadowaki T 2001 The fat-derived hormone adiponectin reverses insulin resistance associated with both lipoatrophy and obesity. Nat Med 7:941-946

16. McGill Jr HC, McMahan CA, Herderick EE, Malcom GT, Tracy RE, Strong JP 2000 Origin of atherosclerosis in childhood and adolescence. Am J Clin Nutr 72:1307S$1315 \mathrm{~S}$

17. Ouchi N, Kihara S, Arita Y, Maeda K, Kuriyama H, Okamoto Y, Hotta K, Nishida M, Takahashi M, Nakamura T, Yamashita S, Funahashi T, Matsuzawa Y 1999 Novel modulator for endothelial adhesion molecules: adipocyte-derived plasma protein adiponectin. Circulation 100:2473-2476

18. Ouchi N, Kihara S, Arita Y, Okamoto Y, Maeda K, Kuriyama H, Hotta K, Nishida M, Takahashi M, Muraguchi M, Ohmoto Y, Nakamura T, Yamashita S, Funahashi T, Matsuzawa Y 2000 Adiponectin, an adipocyte-derived plasma protein, inhibits endothelial NF-kappaB signaling through a cAMP-dependent pathway. Circulation 102:1296-1301

19. Ouchi N, Kihara S, Arita Y, Nishida M, Matsuyama A, Okamoto Y, Ishigami M, Kuriyama H, Kishida K, Nishizawa H, Hotta K, Muraguchi M, Ohmoto Y, Yamashita S, Funahashi T, Matsuzawa Y 2001 Adipocyte-derived plasma protein, adiponectin, suppresses lipid accumulation and class A scavenger receptor expression in human monocyte-derived macrophages. Circulation 103:1057-1063

20. Kappes A, Loffler G 2000 Influences of ionomycin, dibutyryl-cycloAMP and tumour necrosis factor-alpha on intracellular amount and secretion of apM1 in differentiating primary human preadipocytes. Horm Metab Res 32:548-554

21. Eliakim A, Burke G, Cooper DM 1997 Fitness fatness and the effect of training assessed by magnetic resonance imaging and skinfold measurements in healthy adolescent females. Am J Clin Nutr 66:223-231

22. Poehlman ET, Dvorak RV, DeNino WF, Brochu M, Ades PA 2000 Effects of resistance training and endurance training on insulin sensitivity in nonobese, young women: a controlled randomized trial. J Clin Endocrinol Metab 85:2463-2468

23. Eriksson J, Tuominen J, Valle T, Sundberg S, Sovijarvi A, Lindholm H, Tuomilehto J, Koivisto V 1998 Aerobic endurance exercise or circuit-type resistance training for individuals with impaired glucose tolerance? Horm Metab Res 30:37-41

24. Cox JH, Cortright RN, Dohm GL, Houmard JA 1999 Effect of aging on response to exercise training in humans: skeletal muscle GLUT-4 and insulin sensitivity. J Appl Physiol 86:2019-2025

25. Nicholson JF, Pesce M A 2000 Reference Ranges for Laboratory Tests and Procedures-Part I. In: Behrman RE, Kliegman RM, Jenson HB (eds) Nelson Textbook of Pediatrics. WB Saunders, Philadelphia, pp 2184-2222

26. Krafte-Jacobs B, Bock GH 1996 Circulating erythropoietin and interleukin-6 concentrations increase in critically ill children with sepsis and septic shock. Crit Care Med 24:1455-1459

27. Nemet D, Oh Y, Kim HS, Hill MA, Cooper DM 2002 The effect of intense exercise on inflammatory cyotkines and growth mediators in adolescent boys. Pediatrics 110:681-689

28. Scheett TP, Nemet D, Stoppani J, Maresh CM, Newcomb R, Cooper DM 2002 The effect of endurance-type exercise training on growth mediators and inflammatory cytokines in pre-and early pubertal males. Pediatr Res 52:491-497

29. Scheett TP, Milles PJ, Ziegler MG, Stoppani J, Cooper DM 1999 Effect of exercise on cytokines and growth mediators in prepubertal children. Pediatr Res 46:429-434

30. Sack U, Burkhardt U, Borte M, Schadlich H, Berg K, Emmrich F 1998 Agedependent levels of select immunological mediators in sera of healthy children. Clin Diagn Lab Immunol 5:28-32

31. Visser M, Bouter LM, McQuillan GM, Wener MH, Harris TB 2001 Low-grade systemic inflammation in overweight children. Pediatrics 107:E13 